\title{
Robotic lobectomy can be taught while maintaining quality patient outcomes
}

Robert J. Cerfolio, MD, MBA, FACS, FCCP, ${ }^{\mathrm{a}}$ Kyle H. Cichos, BS, ${ }^{\mathrm{b}}$ Benjamin Wei, MD, ${ }^{\mathrm{a}}$ and Douglas J. Minnich, MD

\section{ABSTRACT}

Objective: The objective is to report our outcomes of teaching and performing minimally invasive robotic lobectomy.

Methods: Robotic lobectomy was divided into 19 specific sequential technical maneuvers. The number of steps residents could perform in a set period of time was recorded. Video review by the attending surgeon and coaching were used to improve what residents could safely perform. Outcomes compared were percentage of maneuvers that general surgical or cardiothoracic residents (fellows) completed, operative times, and Society of Thoracic Surgeons-defined metrics of patient outcomes.

Results: There were 520 consecutive robotic lobectomies over 5 years. The various maneuvers completed by general surgical residents $(\mathrm{N}=35)$ and cardiothoracic residents $(\mathrm{N}=7)$ increased over time, for example, steps 1 to 5 increased $20 \%$ and $70 \%$ compared with $80 \%$ and $90 \%(P<.001)$, step 8 increased $0 \%$ and $50 \%$ compared with $90 \%$ and $100 \%(P<.0001)$, and step 19 increased $30 \%$ and $50 \%$ compared with $90 \%$ and $100 \%(P=.001)$, respectively. Operative outcomes, including intraoperative blood loss, median number of lymph nodes, median length of stay, major morbidity, and 30-day and 90-day mortality, were no different. Operative time initially increased and then decreased over time. Conversion to thoracotomy $(15 \%$ to $2.5 \%$, $P=.042)$ and major vascular injury $(3 \%$ to $0 \%, P=.018)$ decreased.

Conclusions: Robotic lobectomy can be safely taught to residents without compromising patient outcomes by dividing it into a series of surgical maneuvers. Recording outcomes for each step and using video review and coaching techniques may help increase the percent of maneuvers residents can complete in a set time. (J Thorac Cardiovasc Surg 2016;152:991-7)

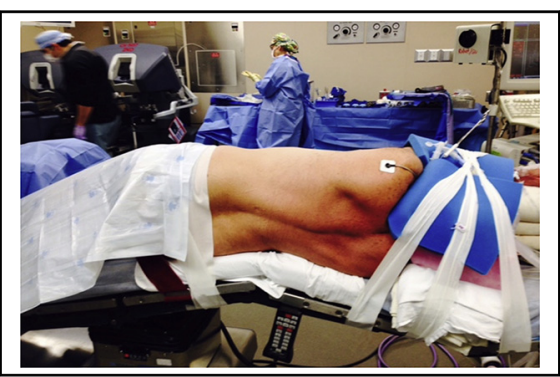

UAB robotic team

Central Message

Robotic lobectomy can be safely taught to residents without compromising patient outcomes by dividing the operation into a series of surgical maneuvers.

Perspective

Robotic lobectomy can be safely taught to residents without compromising patient outcomes by dividing it into a series of surgical maneuvers. Recording outcomes for each step and using video review and coaching techniques may help increase the percent of maneuvers residents can complete in a set time.

See Editorial Commentary page 998

See Editorial page 950.
Teaching minimally invasive lobectomy is difficult given the current health care environment where there is increased scrutiny from quality review boards, hospital administrators, and insurance companies. In addition, patients expect and deserve optimal outcomes. If a major vascular injury

From the ${ }^{\mathrm{a} C a r d i o t h o r a c i c ~ D i v i s i o n, ~ D e p a r t m e n t ~ o f ~ S u r g e r y, ~ U n i v e r s i t y ~ o f ~ A l a b a m a ~ a t ~}$ Birmingham; and ${ }^{\mathrm{b}}$ University of Alabama at Birmingham School of Medicine, Birmingham, Ala.

Received for publication Jan 18, 2016; revisions received April 26, 2016; accepted for publication April 29, 2016; available ahead of print June 9, 2016

Address for reprints: Robert J. Cerfolio, MD, MBA, FACS, FCCP, Cardiothoracic Division, Department of Surgery, University of Alabama at Birmingham, 703 19th St S, ZRB 739, Birmingham, AL 352094 (E-mail: rcerfolio@uabmc.edu). 0022-5223/\$36.00

Copyright (c) 2016 Published by Elsevier Inc. on behalf of The American Association for Thoracic Surgery

http://dx.doi.org/10.1016/j.jtcvs.2016.04.085 occurs during minimally invasive surgery or a conversion to thoracotomy is required, it is reported as an "event" as opposed to the same injury occurring during a thoracotomy. Yet, despite this current environment, it is incumbent on us to teach residents how to safely and efficiently perform minimally invasive lobectomy. Residents expect and deserve to perform parts of the operation despite having increasingly less surgical experience. But patient outcomes

Scanning this QR code will take you to a procedural video.

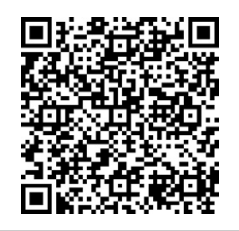




\section{Abbreviation and Acronym \\ $\mathrm{UAB}=$ University of Alabama at Birmingham}

cannot suffer during this process. During our initial learning curve, we were not ready or able to teach robotic lobectomy. Therefore, we developed a systematic approach to both perform and teach it, as well as other robotic thoracic operations, better. We divided each lobectomy into a sequential series of steps or surgical maneuvers and assigned a set amount of time for each step to be completed. We then applied simulation training, coaching techniques, and video review of each step to help improve the steps that residents could not complete. Others have applied similar techniques to surgical training, ${ }^{1}$ but this is the first study of this type that features video review, coaching, and teaching linked to outcomes and time constraints. A major concern is that while teaching robotic surgery, patients can be injured, care is worse, and metrics that are increasingly used as surrogates for quality outcomes suffer. The objectives of this study are to present our results using these teaching methodologies for both general surgical residents and cardiothoracic residents, and to evaluate patient outcomes during our robotic lobectomy experience to ensure it could be taught better while maintaining safety.

\section{MATERIALS AND METHODS}

This is a cohort study using a prospective database from 1 general thoracic surgeon (R.J.C.) on a consecutive series of patients who were scheduled to undergo a robotic lobectomy from February 2010 to December 2015 using the Si robotic system (Intuitive Surgical, Sunnyvale, Calif). Patients who were scheduled for segmentectomy only or wedge resection only were eliminated from this study. Those who underwent a robotic lobectomy were included if wedge resection or segmentectomy was performed first. Our preoperative evaluation included computed tomography scanning, integrated positron emission tomography scanning, and pulmonary function tests as we have previously described., ${ }^{2,3}$ Our robotic operative technique also has been described at length (Figure 1). ${ }^{4}$ The conduct of the operation was reviewed before the start and was broken down into a series of sequential steps similar to our technique for an open lobectomy.

The major classification and description of each chronologic step for the 5 different types of lobectomy are shown in Table 1, as is the amount of time allotted for that step to be performed. The allotted time was derived from our previous experience with open lobectomy and from studying other surgeons' robotic videos. These steps shown are in chronologic order as we perform and teach a lobectomy. The specific subsets involved in each maneuver are not shown. The total operative time is the allotted times (as shown in Table 1 , which when added together equal 80 minutes) and include the desired time to place the ports (10 minutes), dock (5 minutes), place the instruments ( 2 minutes), and close the 5 incisions ( 20 minutes). This yields a total planned operative time of 117 minutes ( $\sim 2$ hours). A robotic right upper lobectomy is shown in Video 1.

\section{Operative Data Collection}

At the end of the operation, we reported the specific steps that each resident was able to complete within the designated time constraints on a data sheet. The data were entered by the attending surgeon before dictating the

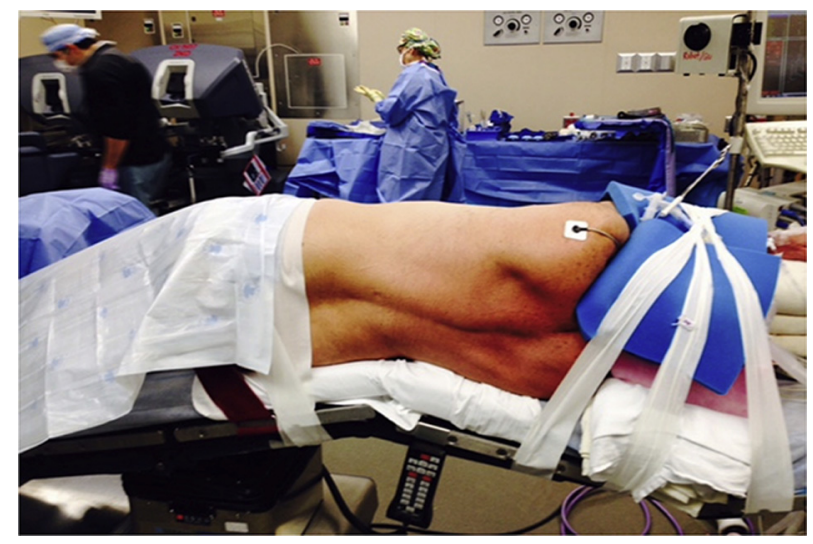

FIGURE 1. Posterior view of patient in right lateral decubitus position.

operative report. We refer to these as teaching outcomes. They were recorded for the general surgical resident and cardiothoracic resident as percentages. General surgical residents were defined as residents who were in the University of Alabama at Birmingham (UAB) 5-year board-approved general surgical residency program. The general thoracic service has 7 third-year postgraduate residents rotate on our service each year. In addition, we had 1 cardiothoracic resident with us per year until 2014 and 2015 when we had 2 each those years. Cardiothoracic residents were defined as those who had matched at the UAB cardiothoracic residency program and were enrolled full time in our 2-year program. Those attendings or fellows or residents who came to UAB as part of advanced training, scholarship programs, or for advanced robotic training after they had completed a cardiothoracic residency were not included in this study. Our previously described training pathway ${ }^{5}$ was used for all residents.

For example, if the resident was able to fully complete the described task in the allotted time, it was recorded as "performed," and if the resident was involved in 1 operation, it would be scored as $100 \%$ for that specific step. If they were involved in 2 operations and only were able to perform step 5 once, their score was $50 \%$ for step 5 . If the resident could not or was not allowed to attempt a task, it was recorded as "not completed," and they would register a $0 \%$ for that task. If a general surgical resident and a cardiothoracic resident were both involved in the same operation, they were both able to receive credit for different parts or even the same part of a lobectomy. For example, step 5 as seen in Table 1 is the removal of the posterior inferior lymph nodes that include lymph nodes number 9,8 , and 7 in that order. Both the general surgical resident and the cardiothoracic resident could receive credit for completing this step if they completed the part ascribed to them. In addition, if the fellow served as the teacher, they both received credit for performing that task or step. A teaching cardiothoracic resident was defined by the attending surgeon (RJC) giving up his robotic console chair to the cardiothoracic resident and he or she taking the general surgeon resident who was on the other console through that part of the operation. During this time, the attending drew on the interactive monitor. If this occurred, both residents were given credit for completing that part of the operation. Attempts were only recorded as completed or not. Operative time was defined as the time between the first skin incision to the time of the last suture placed in the last skin incision. Medical students were involved in the closure of the 5 skin incisions, and a time limit of 20 minutes was established for this part of the operation.

\section{Coaching and Video Review}

Coaching was performed in the operating room and outside. It consisted of working on the technical details of the operation, as well as the mental and emotional aspects of surgery. It varied in time and technique for each 
TABLE 1. The recorded sequential steps of each lobectomy (in order of conduct) and allotted time to be completed

\begin{tabular}{|c|c|c|c|c|c|c|c|}
\hline Step no. & Description & RUL & RML & RLL & LUL & LLL & Allotted time (min) \\
\hline 1 & Mark out ports on skin & Same & Same & Same & Same & Same & 2 \\
\hline 2 & Place ports & Same & Same & Same & Same & Same & 9 \\
\hline 3 & Inspect pleura & Same & Same & Same & Same & Same & 1 \\
\hline 4 & Resect inferior pulmonary ligament & Same & Same & Same & Same & Same & 2 \\
\hline 5 & Remove LNs 9, 8, 7 & Same & Same & Same & Same & Same & 7 \\
\hline 6 & Identify RUL and RLL bronchus posteriorly & Same & Skip this step & Same & $\begin{array}{r}\text { Remove } 10 \mathrm{~L} \\
\mathrm{LN} \text { off PA }\end{array}$ & Same & 5 \\
\hline 7 & Divide fissure between RUL and RLL & Same & $\begin{array}{c}\text { Between RUL } \\
\text { and RML }\end{array}$ & Same & $\begin{array}{l}\text { Divide fissure } \\
\text { between LUL } \\
\text { and LLL }\end{array}$ & $\begin{array}{l}\text { Divide fissure } \\
\text { between LUL } \\
\text { and LLL }\end{array}$ & 10 \\
\hline 8 & Remove LNs $2 \mathrm{R}$ and $4 \mathrm{R}$ & Same & Same & Same & $\# 5$, \#6 & $\# 5$, \#6 & 7 \\
\hline 9 & Retract the lung with robotic arm 3 & Same & Same & Same & Same & Same & 1 \\
\hline 10 & Remove $10 \mathrm{R}$ LN under azygous vein & Same & Same & Same & $\begin{array}{l}11 \mathrm{~L} \text { off PA } \\
\text { and LMSB }\end{array}$ & $\begin{array}{l}11 \mathrm{~L} \text { off PA } \\
\text { and LMSB }\end{array}$ & 1 \\
\hline 11 & Identify and dissect PA arterial branches & Same & Same & Same & Same & Same & 10 \\
\hline 12 & Identify and dissect PV & Same & Same & Same & Same & Same & 5 \\
\hline 13 & Encircle PV & Same & Same & Same & Same & Same & 2 \\
\hline 14 & Encircle PA & Same & Same & Same & Same & Same & 2 \\
\hline 15 & Guide stapler under PA branches & Same & Same & Same & Same & Same & 1 \\
\hline 16 & Guide stapler under pulmonary vein & Same & Same & Same & Same & Same & 1 \\
\hline 17 & Encircle bronchus, guide stapler & Same & Same & Same & Same & Same & 1 \\
\hline 18 & Divide remaining fissure & Same & Same & Same & Same & Same & 10 \\
\hline 19 & Bag specimen & Same & Same & Same & Same & Same & 3 \\
\hline
\end{tabular}

$R U L$, Right upper lobe; $R M L$, right middle lobe; $R L L$, right lower lobe; $L U L$, left upper lobe; $L L L$, Left lower lobe; $L N$, lymph node; $P A$, pulmonary artery; $L M S B$, left main stem bronchus; $P V$, pulmonary vein.

resident. Different coaching styles were used for different residents. Video review was performed by the surgical attending at the end of the day. The parts of the operation that were not completed by the residents were reviewed, and new ways to divide that segment of the procedure were devised and then incorporated into the operative teaching and coaching process. The residents were encouraged to review a copy of the operation at home as well, but because of the 80 -hour work restrictions, there was not a defined, recurring process, or meeting where this was performed as a team with the surgical attending. The Society of Thoracic Surgeons database definitions of length of stay, minor morbidity, major morbidity, 30-day or operative mortality, and 90-day morality were used. ${ }^{6}$

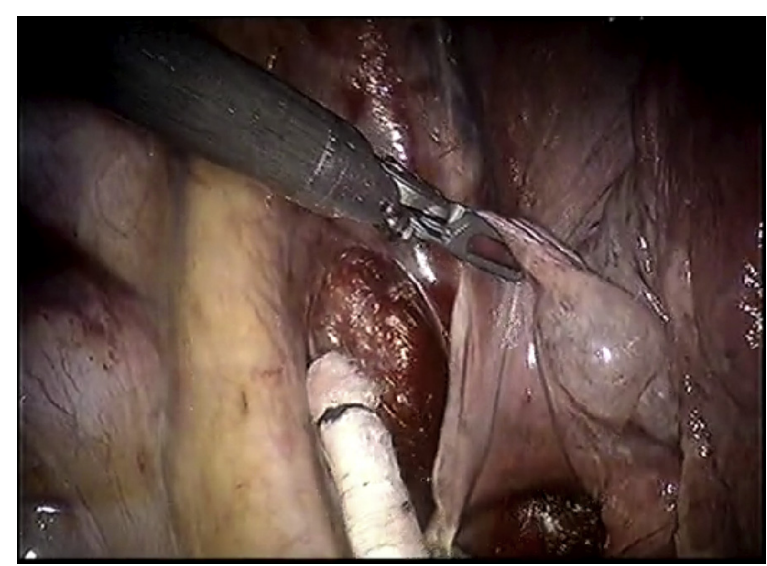

VIDEO 1. Robotic right upper lobectomy is shown. Video available at: http://www.jtcvsonline.org/article/S0022-5223(16)30300-2/addons.

\section{Statistical Analysis and Data Collection}

Information was obtained through hospital databases, medical records, and our prospective database. The UAB's Institutional Review Board approved this protocol, and the prospective database (Institutional Review Board No. X030403013) was used to collect information for this study. Individual consent was waived for inclusion in this study; however, it was required and obtained to enter patient data in the prospective database.

Data were exported from Excel (Microsoft Corp, Seattle, Wash) to SAS v. 9.1 (SAS Institute, Inc, Cary, NC). Continuous data are presented as medians, and categoric data are presented as percentages. Fisher exact test or Pearson's chi-square test was used to assess categoric data, and the Wilcoxon test was used to evaluate continuous variables. Survival estimates were derived by Kaplan-Meier analysis, and log-rank test was used to assess differences in survival among the young and elderly groups. Stratified log-rank analyses and Cox proportional-hazards modeling were used to investigate and adjust for major prognostic and stratification factors. Descriptive statistics are shown by the use of medians, standard deviations, and frequencies as appropriate.

\section{RESULTS}

Between February 2010 and December 2015, there were 1340 consecutive robotic operations performed by 1 thoracic surgeon and 520 underwent robotic lobectomy. There were 255 men with a median age of 65 years (range, 19-89) and 265 women with a median age of 67 years (range, 15-89). For all patients, the median forced expiratory volume in 1 second was $84 \%$ and median diffusing capacity of the lungs for carbon monoxide was $75 \%$; $58 \%$ had hypertension, $41 \%$ had hyperlipidemia, $24 \%$ had coronary artery disease, $19 \%$ had diabetes, 
TABLE 2. Teaching outcomes

\begin{tabular}{|c|c|c|c|c|c|c|}
\hline $\begin{array}{c}\begin{array}{c}\text { Steps } \\
\text { performed }\end{array} \\
\end{array}$ & $\begin{array}{c}\text { Brief description } \\
\text { of steps } \\
\end{array}$ & $\begin{array}{c}\text { Lobectomy } \\
\mathbf{0 - 1 0 0} \\
\% \text { perform } \\
\text { general surgical } \\
\text { resident/thoracic } \\
\text { surgical resident } \\
\end{array}$ & $\begin{array}{c}\text { Lobectomy } \\
101-200 \\
\% \text { perform } \\
\text { general surgical } \\
\text { resident/thoracic } \\
\text { surgical resident } \\
\end{array}$ & $\begin{array}{c}\text { Lobectomy } \\
201-300 \\
\% \text { perform } \\
\text { general surgical } \\
\text { resident/thoracic } \\
\text { surgical resident }\end{array}$ & $\begin{array}{c}\text { Lobectomy } \\
\mathbf{3 0 1 - 4 0 0} \\
\% \text { perform } \\
\text { general surgical } \\
\text { resident/thoracic } \\
\text { surgical resident }\end{array}$ & $\begin{array}{c}\text { Lobectomy } \\
401-520 \\
\% \text { perform } \\
\text { general surgical } \\
\text { resident/thoracic } \\
\text { surgical resident } \\
\end{array}$ \\
\hline Dates & & $2 / 2010-3 / 2011$ & $3 / 2011-4 / 2012$ & $4 / 2012-9 / 2013$ & 9/2013-10/2014 & $10 / 2014-12 / 2015$ \\
\hline Steps $1-5$ & $\begin{array}{l}\text { Ports, ligament, } \\
\text { inferior N2 LNs }\end{array}$ & $\mathrm{NR} / 50 \%$ & $20 \% / 70 \%$ & $60 \% / 70 \%$ & $70 \% / 90 \%$ & $80 \% / 90 \%$ \\
\hline Steps 6-7 & Postbronchus and fissure & $\mathrm{NR} / \mathrm{NR}$ & $0 \% / 20 \%$ & $0 \% / 10 \%$ & $30 \% / 50 \%$ & $20 \% / 60 \%$ \\
\hline Step 8 & Superior N2 LN & $30 \% / 50 \%$ & $60 \% / 75 \%$ & $80 \% / 100 \%$ & $100 \% / 100 \%$ & $90 \% / 100 \%$ \\
\hline Step 9 & Retract lung & $\mathrm{NR} / \mathrm{NR}$ & NR/NR & $0 \% / 15 \%$ & $30 \% / 40 \%$ & $0 \% / 20 \%$ \\
\hline Steps $10-12$ & N1 LN, dissect out PA & $0 \% / 10 \%$ & $0 \% / 60 \%$ & $20 \% / 50 \%$ & $50 \% / 60 \%$ & $40 \% / 70 \%$ \\
\hline Steps $13-14$ & Encircle PV and/or PA & $0 \% / 0 \%$ & $10 \% / 30 \%$ & $30 \% / 70 \%$ & $30 \% / 70 \%$ & $40 \% / 80 \%$ \\
\hline Steps $15-16$ & Staple PA and/or PV & $\mathrm{NR} / \mathrm{NR}$ & $\mathrm{NR} / \mathrm{NR}$ & $0 \% / 0 \%$ & $10 \% / 30 \%$ & $20 \% / 60 \%$ \\
\hline Step 17 & Bronchus & $\mathrm{NR} / \mathrm{NR}$ & $40 \% / 50 \%$ & $30 \% / 70 \%$ & $70 \% / 80 \%$ & $80 \% / 95 \%$ \\
\hline Step 18 & Remaining fissure & $\mathrm{NR} / \mathrm{NR}$ & $\mathrm{NR} / \mathrm{NR}$ & $0 \% / 0 \%$ & $30 \% / 70 \%$ & $50 \% / 70 \%$ \\
\hline Step 19 & Bagging & $15 \% / 40 \%$ & $30 \% / 50 \%$ & $70 \% / 90 \%$ & $90 \% / 100 \%$ & $90 \% / 100 \%$ \\
\hline
\end{tabular}

$L N$, Lymph node; $N R$, not recorded; $P A$, pulmonary artery; $P V$, pulmonary vein.

$23 \%$ had chronic obstructive pulmonary disease, and $78 \%$ were smokers.

Table 2 shows the teaching outcomes for the individual steps of the operation for the general surgical postgraduate year 3 residents $(\mathrm{N}=35)$ and the cardiothoracic residents $(\mathrm{N}=7)$. It demonstrates that the percentage of successful steps per resident over time increased. For example, steps 1 to 5 increased from $20 \%$ and $70 \%$ compared with $80 \%$ and $90 \%(P<.001)$, step 8 increased from $0 \%$ to $50 \%$ compared with $90 \%$ and $100 \%(P<.0001)$, and step 19 increased from $30 \%$ and $50 \%$ compared with $90 \%$ and $100 \%(P=.001)$, respectively.

Table 3 shows that patient outcomes improved or were unchanged: Intraoperative blood loss, median number of lymph nodes, median length of stay, major morbidity, and 30-day and 90-day mortality were no different. Operative time initially increased and then decreased over time. Conversion to thoracotomy ( $15 \%$ to $2.5 \%, P=.042)$ and major vascular injury $(3 \%$ to $0 \%, P=.018)$ decreased, as shown in Figure 2. These outcomes occurred as the residents were performing more of the operations. Figure 3 shows the operative times. It shows a curve that is characterized by an initial decrease in operative time, then a phase as it increases and plateaus, and then it slightly decreases again to approximately a 2-hour skin-to-skin operative time.

\section{DISCUSSION}

Operative efficiency and lean quality and profitable care are the goals of all physicians. ${ }^{7}$ In addition, academic surgeons have to maintain quality outcomes while they teach the art and science of surgery. Teaching minimally invasive surgery, especially robotic surgery, is challenging

TABLE 3. Patient outcomes

\begin{tabular}{|c|c|c|c|c|c|}
\hline Metrics & $\begin{array}{c}\text { Lobectomy } \\
0-100\end{array}$ & $\begin{array}{c}\text { Lobectomy } \\
101-200\end{array}$ & $\begin{array}{c}\text { Lobectomy } \\
201-300\end{array}$ & $\begin{array}{c}\text { Lobectomy } \\
301-400\end{array}$ & $\begin{array}{c}\text { Lobectomy } \\
401-520\end{array}$ \\
\hline Median operative time (skin-to-skin), min & 195 & 160 & 144 & 123 & 126 \\
\hline Median blood loss (range), $\mathrm{mL}$ & $35(15-100)$ & $39(10-3000)$ & $37(10-650)$ & $43(10-400)$ & $47(10-750)$ \\
\hline Median No. of LNs removed (range) & $21(12-25)$ & $21(12-31)$ & $23(13-43)$ & $24(10-34)$ & $24(10-66)$ \\
\hline Median No. of N2 LN stations resected & 5 & 5 & 5 & 5 & 5 \\
\hline Median No. of N1 LN stations resected & 3 & 3 & 3 & 3 & 3 \\
\hline Conversion to thoracotomy & $12 \%$ & $10 \%$ & $7 \%$ & $4 \%$ & $3.3 \%$ \\
\hline Major vascular injury & $2 \%$ & $4 \%$ & $4 \%$ & $3 \%$ & $0 \%$ \\
\hline Transfusion in OR & 0 & 0 & $1 \%$ & 0 & 0 \\
\hline Median length of stay (range), $d$ & $3(1-42)$ & $3(2-12)$ & $3(1-21)$ & $3(1-11)$ & $3(2-11)$ \\
\hline Morbidity of any type & $50 \%$ & $45 \%$ & $12 \%$ & $14 \%$ & $4.2 \%$ \\
\hline Major morbidity & $16 \%$ & $16 \%$ & $5 \%$ & $6 \%$ & $2.5 \%$ \\
\hline 30-d mortality & 0 & 0 & $1 \%$ & 0 & 0 \\
\hline 90-d mortality & 0 & 0 & $2 \%$ & 0 & $0.83 \%$ \\
\hline
\end{tabular}

$L N$, Lymph node; $O R$, operating room. 


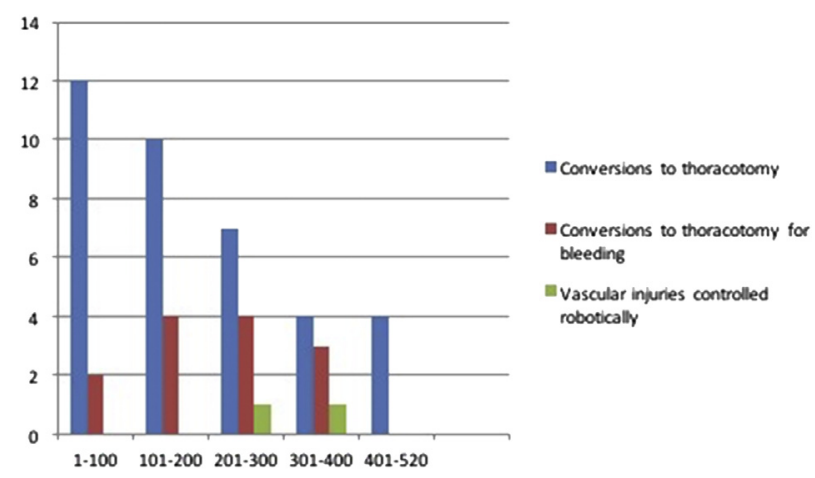

FIGURE 2. Total robotic lobectomies performed with incidence of all conversions and those from bleeding from major vascular injuries $(\mathrm{N}=520)$.

given the risks and the limited availability of the robot. The fear of teaching in the operating room is that patients and quality suffer. Robotic simulators provide training for both novice and experienced surgeons and assess their readiness for surgery. ${ }^{8-10}$

We have taught robotic lobectomy to attending surgeons and residents for more than 6 years and used many strategies, such as video review, teleproctoring, webinars, and novel coaching techniques. In 2012, $\mathrm{Hu}$ and colleagues $^{10}$ described the use of coaching and video reviews in surgical training as a tool to allow surgeons to review their own performance. Our previously published pathway ${ }^{6}$ entails the chronologic progression of (1) online training; (2) cockpit awareness of the robotic console; (3) simulation training; (4) basic skills training; (5) advanced robotic training; (6) team training at UAB; (7) case observations at UAB; (8) teaching of specific operations to teams using cadavers; (9) return to home hospital for progressive proctoring of levels 1,2 , and 3 operations; and (10) coaching, proctoring, and mentoring surgeons via video review. The destination for residents is the same as for attendings, but the pathway is different because the challenges, logistics, and paradigms are different. The first 4 steps of the pathway were used for our residents along with the later steps of coaching, mentoring, and video review. But case observation and traveling to a cadaveric laboratory was not used. Although we were tracking how well we taught attending surgeons, we did not initially track how well (or not well) we taught the process for a specific operation to our residents.

As shown in this study, we chose to teach an operation (lobectomy) on the basis of our perception of the optimal conduct of how best to perform it. Most experienced surgeons do this instinctively, but we have codified it, studied it, and continuously modified the optimal conduct of an operation, which are independent of how to teach it. Teaching a step is based on finding ways to simplify it and break it down into a series of smaller technical steps.

If you can measure something, you can improve it, which also applies to teaching. To improve how we taught, we recorded our success and failure as a teacher. By recording which steps the residents could not safely perform in a preset amount of time, we identified areas as opportunities to teach it better. This may be the most important part of this study. Although it is difficult to prove or assign a precise $P$ value to it, in our opinion, the video review by the attending was the most important factor that led to that improvement. Optimally, video review should be done with the attending and the resident together during a designated time during the day, but we were unable to find time in our program to do this; therefore, the majority was done by the attending at home late at night. The time constraint of each step is important because it prepares the residents for the real world. Although our initial results were extremely disappointing, the mere process of recording teaching outcomes led to improvement in how we taught it and how they learned it.

As shown in this study, we listed 19 basic steps in sequential order for lobectomy. If a resident could not

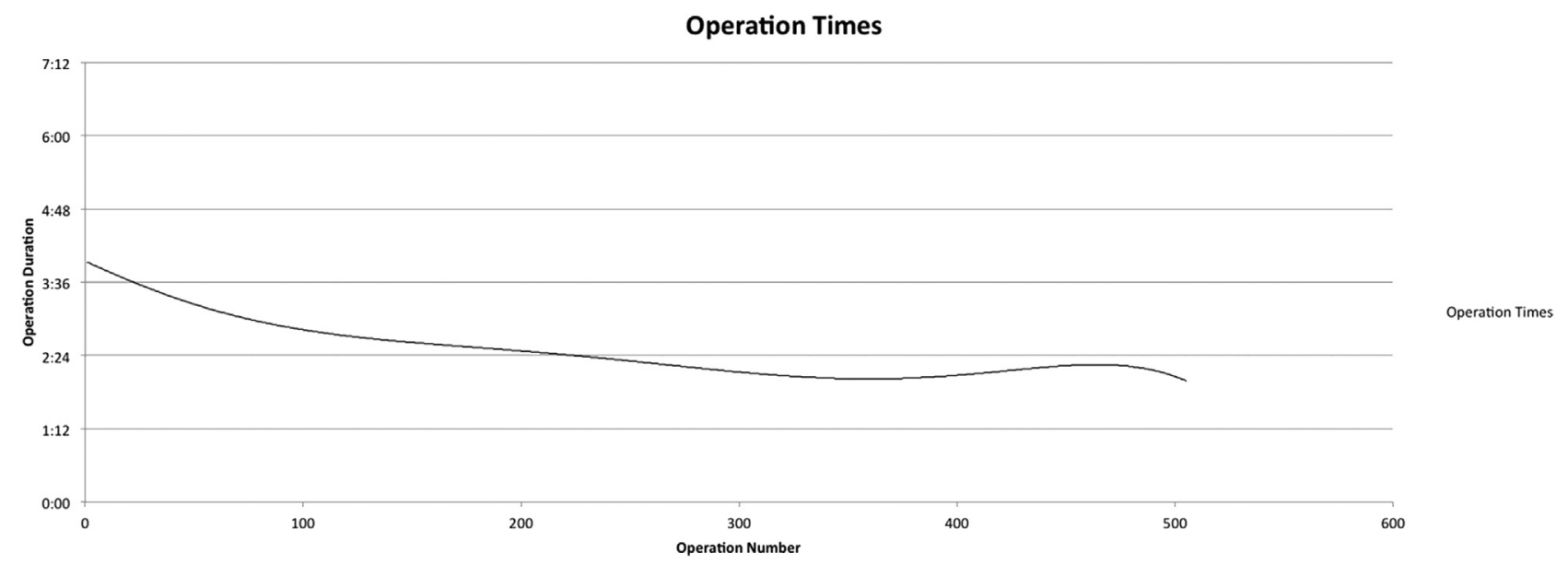

FIGURE 3. Operative times for robotic lobectomy $(\mathrm{N}=520)$. 
complete a particular step, we examined the video, recorded precisely how we positioned all 3 robotic arms and the camera location, and re-reviewed these findings with the resident the next day during the next operation. We came up with ways to teach it better by having the resident duplicate those precise movements. If needed, we subdivided the maneuver they struggled with into smaller and smaller substeps and then reviewed the video again. We believe that this entire process improved our "percent completed" for each step by the resident. However, the process was slow, video review is time-consuming, and improvement is dependent on many variables. In addition, we are not able to prove the benefit of video review given the design of this current study.

\section{Study Limitations and Strengths}

There are many flaws in this study. There are many factors that go into a resident performing a particular part of an operation. These include the residents' skill levels, the amount they have practiced on the robotic simulator, their inability to achieve the same simulator scores before starting with us, their previous robotic experience, their interpersonal relationship with the attending surgeon, the patient risk factors, the attending's patience level at that time, and other patient problems or activities occurring elsewhere at the time of the operation. Although many of these should not influence how much time is spent "letting a resident attempt to complete a step," the reality is that they did in this study. Another flaw is that we do not have data on the amount of simulator time that residents logged or video review time that we or the resident logged. Another flaw entails what constituted successfully completing a maneuver. For example, as noted in the second quintile, the score for encircling pulmonary artery branches was low at $10 \%$ for general surgical residents and only $30 \%$ for cardiothoracic residents. In an initial attempt to increase the scores, we counted it as "successfully taught" when a resident could get under an artery and place a vessel loop around it. However, sometimes we were getting under the artery first with a blunt Cadiere or a long curved tip bipolar dissector and dilating the space and then allowing the resident to pass under the space we had created. Later, in quintiles 4 and 5 we allowed residents to perform the initial dissection under the artery. Another flaw is that at times we had only a general surgical resident on the service, and there was no cardiothoracic resident, and at times we might have 4 or 5 trainees use the console during 1 operation (medical student, general surgical resident, cardiothoracic resident, and an advanced trainee). This is one reason why we believe it best to show the data as "percent performed" over time as opposed to showing the data for each individual resident over time. However, it should be noted that in general, the last 5 cardiothoracic residents all could successfully perform the 19 steps of a straightforward robotic lobectomy.
Although there was a trend for each resident to complete more and more tasks, the variability of each resident's experience, skill level, and number of lobectomies performed, as well as the varying degrees of difficulties of the lobectomy all conspired for other types of statically analysis to be meaningful. In addition, the general resident rotated with us for 6 weeks, and the cardiothoracic resident rotated with us for 3 months. Another flaw is that the amount of time for a task to be completed was not precisely fixed or always tightly measured with a stopwatch, and it too was dependent on many factors, including the patient's risk of the operation, the technical difficulty of the task, the flow of the operation before this task, and even the time of day.

The strengths of this study include that the resident's percent completed was entered into the database just after the operation was completed, and each step was judged as "successful or not" by only 1 person. These factors along with the fact that only 1 operation was studied, lobectomy, minimize common confounding variables. In addition, we corroborated our database with the data that residents reported on their surgical log sheets.

The curve of the operative time as shown in Figure 2 is interesting. It shows several phases. First is the initial decrease in time as we learned how to perform the operation faster. Then as seen in lobectomies 150 to 250 , there is an increase in operative times as we struggled to try to teach it to residents. In the third time frame, cases 250 to 520 , there is an overall decrease in operative time as we learned how to teach it better. However, there are also flaws with these data. Some flaws include the fact that both general surgical and cardiothoracic residents seemed to be more skilled over time as they started to present to us, and second we allowed younger residents to do more over time as we became more comfortable ourselves with the operation and getting out of trouble without conversions.

\section{CONCLUSIONS}

Operations such as robotic lobectomy can be successfully taught by dividing them into a series of surgical maneuvers or steps. Operations can be taught safely without harming patients or reducing metrics that reflect quality care. The outcome of teaching those steps to general surgical and cardiothoracic residents is improved merely by recording what they can and cannot do within a set period of time. Video review and coaching techniques, although difficult to scientifically prove, seem to be a critical part of the improvement process. These processes lead to an increasing "percent completed" by residents. Further studies that scientifically measure "ways to teach" and ways to coach and mentor are needed.

\section{Conflict of Interest Statement}

R.J.C. is a proctor, speaker, and lecturer for Intuitive Surgical; a speaker and teacher for Ethicon; and a consultant to 
Community Health Services, KCL, Bovie, and C-SATS. D.J.M. is a consultant to Medtronic, Inc. All other authors have nothing to disclose with regard to commercial support.

\section{References}

1. Maertens H, Aggarwal R, Desender L, Vermassen F, Herzeele IV. Development of a PROficiency-Based StePwise Endovascular Curricular Training (PROSPECT) Program. J Surg Educ. 2016;73:51-60.

2. Bryant AS, Rudemiller K, Cerfolio RJ. The 30- versus 90-day operative mortality after pulmonary resection. Ann Thorac Surg. 2010;89:1717-23.

3. Cerfolio RJ, Bryant AS. Predictors of survival and disease-free survival in patients with resected N1 non-small cell lung cancer. Ann Thorac Surg. 2007; 84:182-90.

4. Cerfolio RJ, Bryant AS, Skylizard L, Minnich DJ. Initial consecutive experience of completely portal robotic pulmonary resection with 4 arms. J Thorac Cardiovasc Surg. 2011;142:740-6.

5. Cerfolio RJ, Bryant AS. How to teach robotic pulmonary resection. Semin Thorac Cardiovasc Surg. 2013;25:76-82.
6. The Society of Thoracic Surgeons. STS/ACC TVR Registry. Available at: https://www.ncdr.com/TVT/Home/Default.aspx. Accessed May 26, 2016.

7. Liss MA, Abdelshehid C, Quach S, Lusch A, Graversen J, Landman J, et al. Validation, correlation, and comparison of the da Vinci trainer ${ }^{\mathrm{TM}}$ and the da Vinci surgical skills simulator ${ }^{\mathrm{TM}}$ using the Mimic $^{\mathrm{TM}}$ software for urologic robotic surgical education. J Endourol. 2012;26:1629-34.

8. Le CQ, Lightner DJ, VanderLei L, Segura JW, Gettman MT. The current role of medical simulation in American urological residency training programs: an assessment by program directors. J Urol. 2007;177:288-91.

9. Gardner AK, Scott DJ, Pedowitz RA, Sweet RM, Feins RH, Deutsch ES, et al. Best practices across surgical specialties relating to simulation-based training. Surgery. 2015;158:1395-402.

10. Hu Y-Y, Peyre SE, Arriaga AF, Gawande AA, Osteen RT, Swanson RS, et al. Post game analysis: using video-based coaching for continuous professional development. J Am Coll Surg. 2012;214:115-24.

Key Words: education, lung cancer surgery, minimally invasive

Readers who found these articles interesting may also like to read the following papers found in recent and future issues of our sister publications, Seminars in Thoracic and Cardiovascular Surgery and Operative Techniques in Thoracic and Cardiovascular Surgery!

\section{Thoracic: Thoracic Oncology}

Original Submission: The 3-Hole Minimally Invasive Esophagectomy: A Safe Procedure Following Neoadjuvant Chemotherapy and Radiation. Rona Spector. Semin Thorac Cardiovasc Surg 2015; Summer; 27(2): 205-215.

Editorial Commentary: With Minimally Invasive Esophagecomty, Thoracic Surgeons Must Avoid Falling Into the Same Trap Again. Thomas Ng. Semin Thorac Cardiovasc Surg 2015; Summer; 27(2):216.

Original Submission: Maximal Oxygen Uptake - Risk Predictor of NSCLC Resection with Comorbid Emphysema: Lessons from NETT. Ian Makey. Semin Thorac Cardiovasc Surg 2015; Summer; 27(2):225-224.

Editorial Commentary: How Can the NETT Provide Guidance in Risk Stratification for Patients with Severe Emphysema and Early Stage NSCLC? Michael Hsin. Semin Thorac Cardiovasc Surg 2015; Summer; 27(2):232-233.

State of the Art: Induction Therapy for Mesothelioma. Isabelle Schmitt-Opitz. Semin Thorac Cardiovasc Surg 2015; Summer; 27(2):240-250. 